\title{
Aktivitas masyarakat jawa dalam novel Bumi Manusia karya Pramoedya Ananta Toer: Kajian antropologi sastra
}

\author{
Bebryana Ratri ${ }^{1, a}$, Sarwiji Suwandi ${ }^{2,}$, Andayani ${ }^{3, c}$ \\ a Pendidikan Bahasa dan Sastra Daerah, Pascasarjana, Universitas Sebelas Maret \\ ${ }^{\text {b }}$ Pendidikan Bahasa dan Sastra Daerah, Pascasarjana, Universitas Sebelas Maret \\ ${ }^{\mathrm{C}}$ Pendidikan Bahasa dan Sastra Daerah, Pascasarjana, Universitas Sebelas Maret \\ ${ }^{1}$ bebryanar@gmail.com; sarwijiswan@yahoo.com; bu_anda09@yahoo.co.id \\ *korespondensi penulis
}

\begin{tabular}{ll}
\hline Informasi artikel & \\
\hline Sejarah artikel: & \\
Diterima & : 7 Maret 2020 \\
Revisi & : Oktober 2020 \\
Dipublikasikan & : Oktober 2020 \\
\hline
\end{tabular}

Kata kunci:

Aktivitas

Jawa

Novel

Antropologi

\begin{abstract}
ABSTRAK
Penelitian ini bertujuan untuk mendeskripsikan wujud budaya kompleksitas aktivitas yang terdiri atas aktivitas kekerabatan, ekonomi, pendidikan, keindahan dan rekreasi, religi, politik, dan kebutuhan jasmani dalam novel Bumi Manusia karya Pramoedya Ananta Toer. Pendekatan yang digunakan dalam penelitian ini adalah pendekatan antropologi sastra. Baca catat, kepustakaan, dan deskripsi analisis merupakan metode pengumpulan data dalam penelitian ini. Sedangkan teknik analisis data yang digunakan berupa analisis deskriptif kualitatif. Hasil penelitian yang diperoleh yaitu (I) aktivitas kekerabatan: tolong menolong, bertamu dan peduli antarmanusia, (2) aktivitas ekonomi: melengkapi kebutuhan hidup manusia, (3) aktivitas pendidikan: formal yaitu bersekolah di institusi dan non formal, (4) aktivitas keindahan dan rekreasi: bidang seni gerak dan seni suara yang dilakukan oleh tokoh, (5) aktivitas religi atau keagamaan: perkawinan yang sah secara islam dan saling menghargai setiap kepercayaan antar tokoh walau berbeda agama, (6) aktivitas politik: bidang pemerintahan dan organisasi, dan (7) aktivitas kebutuhan jasmani atau somatis: bidang makanan, minuman, dan pakaian.

ABSTRACT

This research aims to describe the complexity cultures consisting of kinship activities, economy, education, beauty and recreation, religion, politics, and physical needs in the novel Bumi Manusia written by Pramoedya Ananta Toer. The approach used in this research is the anthropology literature approach. Read notes, literature, and description of the analysis are methods used in collecting the data. Meanwhile, the data analysis technique used is descriptive qualitative analysis. The results obtained are (I) kinship activities: helping each other, visiting houses and caring among human, (2) economic activities: complementing the needs of human life, (3) educational activities: formal and non formal, (4) beauty and recreation activities: the art of motion and the art of sound done by human, (5) religious activities: marriage and mutual respect for every beliefs between people, (6) political activities: the fields of government and organization, and (7) physical needs activities: the fields of food, beverages, and clothing.
\end{abstract}

Key word:

Activities

Javanese

Novels

Anthropology

Copyright (C) 2018 Universitas Ahmad Dahlan. All Right Reserved

\section{Pendahuluan}

Novel Bumi Manusia karya Pramoedya Ananta Toer merupakan sebuah novel inspirasi yang banyak mengandung pesan bagi pembaca tentang masalah kehidupan. Novel ini pula dijadikan film yang ditayangkan di bioskop, film tersebut disutradarai oleh Hanung Bramantyo. Novel Bumi Manusia ini menceritakan tentang kehidupan Minke sebagai masyarakat pribumi yang mencintai Annelies gadis
Indo. Minke merupakan laki-laki kelahiran Jawa yang sekolah di H.B.S. Sekolah tersebut didominasi oleh masyarakat Eropa yang tinggal di Indonesia. Oleh karena itu, gaya Minke sudah seperti orang Eropa. Sementara Annelies wanita Indo ini lebih suka dikenal sebagai pribumi seberti sang ibu yang bernama Nyai Ontosoroh. Akhirnya, setelah beberapa lama Minke dan Annelies kenal, mereka melangsungkan pernikahan dengan adat Jawa.

Aktivitas masyarakat Jawa yang terdapat dalam novel Bumi Manusia sangat menarik. Masyarakat Jawa 
atau yang biasa dikenal sebagai pribumi dalam novel tersebut bekerja sebagai petani atau berternak. Pribumi tidak mengurus ladang atau berternak milik sendiri melainkan milik masyarakat Indo yang berkuasa. Aktivitas masyakat Jawa perlu diteliti karena hingga saat ini pun sebagian masyarakat Jawa masih bertani dan berternak.

Aktivitas masyarakat lainnya yaitu bersekolah walau hanya beberapa pribumi yang dapat merasakan bangku sekolah. Pendidikan memang penting tetapi hanya beberapa saja yang dapat sekolah. Jadi masyarakat Jawa masih banyak yang belum bisa membaca.

Aktivitas pribumi pun terdapat dalam bidang keagamaan. Agama yang dianut dalam tokoh berbedabeda. Mereka menjalankan seuai dengan kewajiban masing-masing. Toleransi terhadap setiap tokoh pun cukup tinggi dan saling menghargai satu sama lain dan dapat hidup berdampingan dengan damai.

Pendekatan antropologi sastra sebagai studi sastra dengan manusia mengkaji aktivitas-aktivitas yang terdapat dalam novel Bumi Manusia karya Pramoedya Ananta Toer. Pendekatan antropologi sastra memiliki ini berkaitan dengan kebudayaan. Sementara itu, Ratna (2012: 43-44) berpendapat bahwa antropologi sastra merupakan macam dari analisis wacana, bahkan antropologi sastra terkenal dengan kajian budaya.

Antropologi sebagai ilmu yang sangat luas yang mempelajari aspek kehidupan dari lingkungan biologi dan perubahan pada kapasitas kebudayaan, untuk kehidupan yang lebih bervariasi melalui lensa budaya. Setiap manusia disosialisasikan dengan langkah khusus untuk melihat dunia dan merespon terhadap dunia, secara tingkah laku melalui budaya (Waterston \& Vesperi, 201 I: I3).

Penelitian yang menggunakan kajian antropologi telah dilakukan juga sebelumnya. Corak unsur antropologi sastra dalam cerita rakyat Datumuseng dan Maia Daepati, yaitu bahasa, religi, mitos, hokum, dan adat istiatadat merupakan topik penelitian Djirong (2014). Penelitian yang sama dilakukan oleh Rasyid (2017) tentang unsur lokalitas yang terdapat dalam cerita rakyat Datumuseng dan Maipa Daepati, yaitu bahasa, adat istiadat, wilayah, dan symbol mitologi serta pola pikir masyarakatnya. Kemudian, Perbawani (2019) membahas tentang kompleksitas hasil budaya yang terdapat dalam cerita rakyat atau folklore yang berjudul Payaman Cave menggunakan kajian antropologi sastra.

Selanjutnya, penelitian Sahlan (2012) membahas tentang kandungan nilai-nilai kearifan lokal yang digunakan dan diterapkan oleh masyarakat Buton secara turun temurun. Terdapat pula penelitian yang mengkaji mengenai pemertahanan budaya Tionghoa dalam novel Kau, Aku dan Sepucuk Angpau Merah karya Tere Liye yang menggunakan pendekatan antropologi sastra, yaitu penelitian milik Juliastuty (2013). Kemudian, nilai-nilai budaya Sarapatanguna dalam kepemimpinan pemerintahan di Kota Baubau, Provinsi Sulawesi Tenggara dibahas oleh Bagea (2016). Penelitian ini berlandaskan teori antropologi sastra. Antropologi memperlajari tentang manusia secara nyata, tetapi juga membaca tentang sastra. Semua aspek budaya manusia dan masyarakat sebagai kelompok variable yang berinteraksi merupakan pokok bahasan antropologi. Sedangkan sastra adalah cerminan tentang kehidupan manusia (Ihsan \& Zuliyanti, 2018: 33). Antropologi sastra merupakan kajian yang menekankan pada warisan budaya pada masa lalu yang masih Nampak pada karya sastra sehingga dapat dikaji melalui paparan etnografi yang ada pada karya sastra tersebut sebagai data (Juliastuty, 2013: 343).

Selanjutnya, menurut Rasyid (2017: 28) antropologi memiliki arti suatu pengetahuan terhadap perilaku manusia. Antropologi merupakan aspek budaya manusia dan masyarakat sebagai kelompok variable yang berinteraksi. Sedangkan sastra diyakini sebagai cermin kehidupan masyarakat pendukungnya.

Antropologi juga menekankan beberapa tema terpisah yang saling berkaitan. Antropologi juga memberi perspektif pada zaman sekarang yang mampu mencoba menghilangkan regulasi atau peraturan (Chrisman \& Maretzki, I982: 3). Sastra mencerminkan budaya dan bahkan novel yang ditulis dengan buruk dapat menjadi potret yang menarik dari budaya tertentu dan nilai dokumenternya tidak diragukan lagi akan meningkat seiring bertambahnya usia (Poyatos, I988: I5).

Antropologi sebagai studi tentang umat manusia, berusaha menyusun generalisasi yang bermanfaat tentang manusia dan perilakunya dan untuk memperoleh pengertian lengkap tentang keanekaragaman manusia (Haviland, I995: 7). Antropologi dan sastra memiliki kontribusi pada ilmu pengetahuan yang menggambarkan pikiran sosial dan aktivitas antarbudaya (Ashaley, I990: 9).

Rasyid (2017: 28) menerangkan bahwa antropologi sastra menjadi salah satu teori sastra yang 
menelaah hubungan antara sastra dan budaya terutama untuk mengamati bagaimana sastra itu digunakan dalam kehidupan sehari-hari sebagai alat dalam tindakan bermasyarakat. Kajian antropologi dapat menghubungkan novel, cerpen, puisi drama, dan cerita rakyat dengan konsep situasi sosial budayanya.

Antropologi merupakan suatu disiplin yang berdasarkan rasa ingin tahu yang tiada hentihentinya tentang umat manusia (Ihrom, 2006: I). Koentjaraningrat (2015: I50) juga berpendapat kebudayaan terbagi menjadi tiga wujud yaitu (I) kompleksitas ide, norma, gagasan, nilai dan peraturan, (2) kompleksitas aktivitas serta tindakan berpola dari manusia dalam masyarkat, dan (3) wujud fisik atau benda karya manusia.

Wujud kompleksitas aktivitas ini lebih fokus pada "pranata" yang menjadi pola aktivitas manusia. Menurut Koentjaraningrat (2015: I63), pranata sebagai keperluan kehidupan masyarakat yang sesuai dengan sistem norma khusus yang menata suatu aktivitas atau rangkaian kegiatan budaya.

Para ahli sosiologi telah menggolongkan pranata berdasarkan fungsi dari pranata-pranata untuk memenuhi keperluan hidup manusia sebagai masyarakat (Koentjaraningrat 2015: I35). Pranata-pranata tersebut yaitu aktivitas kekerabatan, ekonomi, pendidikan, keindahan dan rekreasi, religi, politik, kebutuhan jasmani.

Berdasarkan penjelasan di atas, maka penelitian ini membahas tentang kompleksitas aktivitas masyarakat Jawa yaitu kompleksitas aktivitas terdiri dari kekerabatan, ekonomi, pendidikan, keindahan dan rekreasi, religi, politik, kebutuhan dan jasmani dalam novel Bumi Manusia karya Pramoedya Ananta Toer.

\section{Metode}

Metode penelitian yang digunakan adalah deskriptif kualitatif. Penelitian deskriptif kualitatif bertujuan untuk memahami aktivitas tentang apa yang dialami subjek penelitian, misalnya deskriptif, perilaku, persepsi, motivasi, dan tindakan dalam bentuk dialog, narasi, dan kutipan konteks khususnya yang alamiah dengan memanfaatkan berbagai metode ilmiah (Moleong, 20I4: 6). Bentuk penelitian ini digunakan untuk menggambarkan aktivitas masyarakat Jawa. Teknik pengumpulan data dalam penelitian ini menggunakan metode baca catat, kepustakaan dan deskripsi analisis.
Instrumen merujuk pada alat yang merujuk kepada sarana pengumpulan data (Siswantoro, 2005: I33). Instrumen yang digunakan adalah kartu data. Kartu data digunakan untuk mencacat hal-hal penting yang berkaitan dengan aktivitas masyarakat Jawa. Peneliti atau pengumpul data juga termasuk dalam instrumen penelitian. Peneliti sebagai instrumen kegiatan pengumpulan data yang tidak dapat dilakukan melalui perantara atau sarana orang lain. Sumber data yang terdapat pada teks akan langsung dikumpulkan oleh peneliti (Siswantoro, 2005:65).

Menurut Creswell (2010: 243-270) teknik analisis data merupakan suatu proses yang mengatur rangkaian data dengan menggolongkan ke dalam suatu kategori, satuan rangkaian dasar dan pola. Penelitian ini menganalisis data yang menggunakan teknik analisis model alir. Langkah-langkah analisis data model alir menurut Miles \& Huberman (20I2:15-19) yaitu reduksi data, sajian data, penarikan kesimpulan dan verifikasi.

\section{Hasil dan Pembahasan}

Berikut ini pembahasan tentang kompleksitas aktivitas terdiri dari kekerabatan, ekonomi, pendidikan, keindahan dan rekreasi, religi, politik, dan kebutuhan jasmani dalam novel Bumi Manusia karya Pramoedya Ananta Toer.

\section{Aktivitas Kekerabatan}

Analisi ini mengenai aktivitas kekerabatan merupakan aktivitas yang berkaitan dengan kekerabatan. Hubungan kekerabatan bukan hanya semata-mata lahir karena adanya hubungan darah, tetpai juga karena adanya kedekatan antarmanusia.

Aktivitas kekerabatan yang terwujud dalam novel tersebut sangat beragam. Berikut ini aktivitas masyarakat yang sedang bertamu.

"Aku mau bertanya, bagaimana bisa kau tinggal di sini? Nampaknya senang pula? Karena ada Annelies?"

"Betul, Rob, karena ada adikmu, Juga karena dipinta." (Bumi Manusia, 20I9, hlm. I55).

Minke sedang bertamu kerumah Annelies. Kemudian kakak dari Annelies yang bernama Robert menanyakan keberadaan Minke. Sementara itu, Minke bertamu kerumah Annelies karena diminta oleh yang punya rumah. Jadi, aktivitas tersebut akan menambah keakraban antarmanusia. Beikur ini data yang menunjukkan tolong menolong.

Sejak pagihari orang telah sibuk menyiapkan tempat untuk resepsi pengangkatan Ayahanda. (Bumi Manusia, 2019, hlm. 195). 
Kutipan tersebut menunjukkan bahwa adanya aktivitas masyarakat yang memiliki kedekatan antarmanusia. Masyarakat sedang membantu mempersiapkan acara pengangkatan sebagai Bupati. Aktivitas tersebut merupakan aktivitas yang dilakukan untuk menambah dan menjaga hubungan antarmanusia agar menjadi lebih baik.

Data selanjutnya menunjukkan aktivitas tolong menolong antarmanusia. Terdapat beberapa kutipan yang menggambarkan adanya aktivitas tersebut

Setiap hari aku memerlukan datang ke rumah Jean menjemput atau mengantarkan May atau menyerahkan order baru (Bumi Manusia, 2019, hlm. 324).

Ketika memiliki sahabat yang tidak sempurna maka harus saling tolong menolong. Jean merupakan seseorang yang tidak bias berjalan atau biasa dikatakan pincang maka setiap hari Minke perlu membantu untuk mengantar May anak Jean untuk berangkat ke sekolah. Aktivitas tersebut merupakan adanya rasa kekerabatan antar sahabat. Data selanjutnya yang menunjukkan adanya aktivitas dengan seseorang dokter keluarga dan pasien yang bernama Annelies.

"Beberapa kali Dokter Martinet masih datang berkunjung. Biasanya pada sorehari bila Nyai Ontosoroh dan Annelies sudah selesai bekerja (Bumi Manusia, 20I9, hlm. 384).

Wujud aktivitas di atas dokter Martinet selalu melihat kondisi Annelies walau sedang sakit atau tidak. Dokter Martinet pun datang disaat Nyai Ontosoroh dan Annelies sudah selesai bekerja.

Bagaimana kiranya kalau dia sering kemari seperti anjuran Dokter Martinet tadi?"

"Kalau anaknya suka, tentu tak ada halangan," suaranya murung seakan takut kehilangan.

"Minke, Nyo, undanglah Tuan Marais menginap." (Bumi Manusia, 2019, hlm. 390)

Dokter Martinet ini mrupakan dokter keluarga Annelies. Jadi menurut dokter bahwa kehadiran Minke akan membuat keadaan Annelies membaik. Oleh karena itu, Dokter Martinet menyarankan untuk Minke menginap di rumah Nyai Ontosoroh.

Data selanjurnya aktivitas hubungan kekerabatan yang dibangun dari aktivitas pernikahan untuk menambah dan menjaga hubungan baik antarkeluarga. Berikut ini merupakan kutipan tersebut.

Beberapa hari sebelum upacara pernikahan Bunda datang sebagai satu-satunya wakil keluargaku (Bumi Manusia, 2019, hlm. 450).

Kutipan diatas menunjukkan aktivitas kekerabatan untuk membangun silaturahmi antar keluarga, hal ini ditunjukkan dengan aktivitas pernikahan. Minke dan Annelies melangsungkan pernikahan dan Bunda atau Ibu dari Minke datang sebagai wali dari keluarganya.

"Kami gembira kau datang, Rob, "kataku (Bumi Manusia, 2019, hlm. 47I).

Kehadiran Rob saat perta pernikahan Minke dan Annelies merupakan suatu kebahagiaan. Rob merupakan seseorang yang mengenalkan Minke terhadap Annelies.

Berdasarkan penjabaran di atas dalam novel Bumi Manusia ditemukan beberapa kutipan dan dialog yang berhubungan dengan adanya aktivitas kekerabatan yaitu, aktivitas pernikahan dan tolong menolong.

\section{Aktivitas Ekonomi}

Aktivitas ekonomi adalah aktivitas yang berhubungan dengan keperluan, kebutuhan, dan keberlangsungan hidup. Berikut ini beberapa kutipan data yang menunjukkan aktivitas ekonomi.

Itulah untuk pertama kali kuketahui, gadis cantik kekanak-kanakan ini ternyata seorang pengawas yang harus diindahkan oleh para pekerja, lelaki dan perempuan (Bumi Manusia, 2019, hlm. 44).

Kutipan tersebut menunjukkan aktivitas ekonomi dalam upaya mempertahankan perusahaan dan untuk memenuhi kebutuhan hidup. Annelies merupakan wanita cantik keturunan Eropa dan memiliki sikap manja, tetapi Annelies sudah bekerja sejak kecil dan sekarang ia bekerja sebagai pengawas atau mandor di lahan pertaniannya.

"Kau memandori mereka?" tanyaku.

"Perahanku sendiri tetap lebih banyak," jawabnya (Bumi Manusia, 2019, hlm. 47). 
Selain sebagai mandor Annelies juga bekerja memerah sapi-sapi yang terdapat dalam perusahaan dan hasil perahannya jauh lebih banyak dari karyawannya. Demikian dialog tersebut menunjukkan aktivitas ekonomi dalam bidang peternakan. Data selanjutnya menunjukkan adanya aktivitas ekonomi dalam bidang seni.

"Tuan Tollenar, kami tuntut jadi pembantu kami, pembantu tetap," ia sodorkan kwitansi dan kuterima honoraria dari tulisan yang sudah-sudah, sekalipun tidak banyak." Setelah ini, sebagai pembantu tetap, Tuan akan menerima lenbih banyak." (Bumi Manusia, 2019, hlm. 47).

Minke atau Max Tollenar adalah seorang yang bekerja sebagai penulis. Minke mendapatkan tawaran untuk menulis di sebuah percetakan dan sebagai penulis tetap yang harus selalu mengirimkan tulisan tentang apa saja. Demikian dapat disimpulkan bahwa aktivitas ekonomi dilakukan semata-mata untuk melengkapi kebutuhan hidup.

\section{Aktivitas Pendidikan}

Wujud budaya aktivitas dalam bidang pendidikan adalah kegiatan mendidik, mengajarkan, memberi, berbagai ilmu dan pegetahuan. Aktivitas pendidikan dapat berupa pendidikan formah maupun non formal. Aktivitas pendidikan yang terdapat dalam novel Bumi Manusia karya Pramoedya Ananta Toer mencakup aktivitas pendidikan formal mapun non formal yang dilakukan untuk menyalurkan informasi, ilmu, nilai-nilai kepada orang lain. Berikut ini datadata yang ditemukan.

Kemudian mulailah kami mendapat pelajaran Inggris. Enam bulan lamanya, dan aku temukan kesamaan bunyi dan huruf pada namaku. (Bumi Manusia, 2019, hlm. 52).

Kutipan di atas menunjukkan adanya aktivitas pendidikan di masyarakat. Minke belajar di sekolah masyarakat Eropa maka dari itu ia mendapatkan pelajaran Bahasa Inggris sebelum memulai sekolah.

"Bagaimana sekolahmu? Buat kepentingan May dan aku kau tak pernah sempat belajar di rumah. Aku kuatir...."

"Beres, Jean. Ujian selalu aku lalui dengan selamat." (Bumi Manusia, 2019, hlm. 90).

Aktivitas di atas merupakan dialog yang menunjukkan aktivitas Minke yang dapat menjalankan ujian di sekolah dengan baik. Aktivitas pendidikan tersebut merupakan aktivitas pendidikan formal.

\section{Aktivitas Keindahan dan Rekreasi}

Aktivitas keindahan dan rekreasi merupakan aktivitas yang memenuhi kebutuhan manusia yang berkaitan dengan seni rupa, seni suara, seni gerak, seni drama, kesusastraan dan lain-lain. Berikut ini kutipan yang mendeskripsikan aktivitas pendidikan.

Penari-penari tercantik dan terbaik seluruh kebupatian kabarnya telah disewa untuk keperluan itu. Ayahanda telah mendatangkan gamelan terbaik dari perunggu tulen dari kota T; gamelan Nenenda, yang terbungkus beledu merah bila tak ditabuh (Bumi Manusia, 2019, hlm. 195).

Kutipan tersebut menunjukkan adanya aktivitas keindahan yang dilakukan Ayahanda dengan mendatangkan penari-penari sebagai pengisi acara saat pengangkatan sebagai bupati. Semua orang yang datang menikmati seni tari yag dipertunjukkan. Dara berikut ini merupakan seni suara.

Lagu kebangsaan Belanda, Wilhelmus, dinyanyikan. Orang berdiri (Bumi Manusia, 2019, hlm I99).

Gamelan memainkan Kebo Giro, lagu selamat dating, menggebu-gebu memenuhi ruangan resepsi dan hati (Bumi Manusia, 2019, hlm. 199).

Gamelan merupakan alat musik tradisional yang akan dimainkan untuk mengiringi Kebo Giro. Gamelan Kebo Giro biasanya untuk mengiringi upacara pernikahan yang memiliki makna tentang gerak dan tingkah kerbau aktaktif. Selanjutnya, data mengenai seni gerak, sebagai berikut.

Para lurah, wedana, mantri, polisi, menyerbu pendopo, dan tayub berlangsung sampai pagi dengan seruan bosee setiap teguk minuman keras.... (Bumi Manusia, 2019, hlm. 202).

Beberapa orang penting dan terpandang pun menghadiri perayaan tersebut. Masyarakat tersebut pun menikmati tarian yang ada hingga pagi hari. Berdasarkan penjelasan di atas yang berkaitan dengan aktivitas tokoh dalam bidang keindahan dan rekreasi dalam novel Bumi Manusia yang berkisan pada seni gerak.

\section{Aktivitas Religi}

Aktivitas religi merupakan aktivitas yang dilakukan sesuai dengan kepercayaan atau keyakinan 
seseorang. Keyakinan dan kepercayaan dapat ditujukkan kepada Tuhan. Terdapat beberapa data yang menunjukkan aktivitas religi dalam novel Bumi Manusia karya Pramoedya Ananta Toer. Berikut ini data yang menunjukkan aktivitas religi yang dilakukan oleh tokoh dalam novel.

"Tamuku Islam," kata Annelies dalam Jawa pada pelayannya. "Katakan di belakang sana, jangan sampai tercampur babi." (Bumi Manusia, 2019, hlm. 35).

Kutipan tersebut menunjukkan aktivitas religi yang dilakukan oleh tokoh. Minke merupakan yang beragama Islam sementara itu Minke sedang berada di lingkungan yang beragama non Islam maka Annelies berpesan pada seseorang yang memasak agar tidak memberikan makanan babi. Makanan tersebut dalam agama Islam tidak diperbolehkan untuk dimakan.

Kami dinikahkan secara Islam. Darsam bertindak sebagai saksi dan sekaligus wali menurut hukum Islam bagi Annelies (Bumi Manusia, 20I9, hlm. 45I).

Minke dan Annelies melangsungkan pernikahan secara Islam. Darsam bertindak sebagai saksi pernikahan mereka. Pernikahan mereka sah secara agama tetapi belum dalam hukum. Aktivitas religi yang dilakukan dalam novel daapat termanivestasi atas perlakuan dan kepercyaan tokoh pada suatu hal.

\section{Aktivitas Politik}

Aktivitas politik ini bertujuan untuk memenuhi kebutuhan masyarakat dalam mengatur kehidupan berkelompok dan bernegara. Ativitas politik meliputi pemerintahan, demokrasi, kehakiman, kepartaian, dan sebagainya. Berikut ini beberapa data yang terdapat dalam novel tersebut.

Mengapa pada umumnya Pribumi dari Purworejo? Sekali waktu aku pernah bertanya. Mereka itu, jawabnya, orang-orang yang tenang. Kompeni memilih mereka untuk menghadapi bangsa Aceh bukan saja pandai menggertak, juga ulet dan keras seperti baja, bangsa perbuatan (Bumi Manusia, 20I9, hlm. 86).

Kutipan di atas menunjukkan aktivitas bahwa masyarakat asli Purworejo dipilih menjadi kompeni untuk menghadapi aceh karena mereka memiliki sifat yang tenang, berani, rajin dan kuat seperti baja. Berikut ini data aktivitas politik yang lain.
Maka pengadilan akan menghadapkan Babah Ah Tjong sebagai terdakwa. Pengadilan Putih, Pengadilan Eropa! Bukan karena Ah Tjong punya forum privilegiatum, tapi karena adanya connexiteit sebagaimana aku ketahui duduk-perkaranya di kemudianhari. Ia dituduh dengan sengaja dan direncanakan telah membunuh Herman Mellema baik secara perlahan-lahan maupun sekaligus (Bumi Manusia, 2019, hlm. 418).

Pengadilan Putih atau Pengadilan Eropa telah menetapkan Ah Tjong sebagai tersangka. Tuan Herman Mellema sebagai pelanggan setia Ah Tjong kemudian beliau mati ditempat pelesiran Ah Tjong. Ah Tjong dituduh membunuh secara perlahan maupun tidak. Pengadilan Putih pada umunya akan lebih membela masyarakat yang sama dengan mereka. Berdasarkan penjelasan di atas dapat disimpulkan terdapat aktivitas politik dalam novel tersebut meliputi aktivitas pemerintahan dan organisasi.

\section{Aktivitas Kebutuhan Jasmani}

Kompleksitas aktivitas dalam bidang kebutuhan jasmani merupakan kegiatan yang berkaitan dengan pemenuhan kebutuhan jasmani. Kebutuhan jasmani dapat berupa kebutuhan primer maupun sekunder. Kebutuhan primer meliputi makan, minum, rumah, dan pakaian, Sementara itu kebutuhan sekunder berupa alat transportasi, perawatan kecantikan, perhiasan, dan sebagainya. Adapun aktivitas jasmani dalam novel tersebut, berikut ini kutipan-kutipan yang terdapat dalam novel Bumi Manusia.

Hidangan itu berlebih-lebihan. Yang pokok adalah sapi muda, makanan baru untuk pertama kali kucicipi dalam hidupku (Bumi Manusia, 2019, hlm. $4 I)$.

Kutipan di atas membahas tentang aktivitas jsmani sebagai kebutuhan manusia yang berkaitan dengan makan. Annelies menyiapkan makanan yang sangat banyak untuk Minke sebagai tamu. Makanan utama yang disediakan yaitu sapi muda yang belum pernah ia makan sebelumnya. Makanan sebagai kebutuhan setiap manusia untuk menambah suatu energi.

Seseorang datang menjenguk. Aku pura-pura tak tahu. Secangkir kopi hitam disuguhkan. Kuteguk habis (Bumi Manusia, 2019, hlm. I87). 
Narasi tersebut menunjukkan aktivitas kebutuhan manusia berkaitan dengan minuman. Minuman yang disiapkan oleh seseorang untuk Minke saat di kamar. Minuman kopi bagi sebagian orang sebagai minuman wajib dan ada pula yang beranggapan bahwa minuman tersebut dapat menyebabkan sulit tidurDemikian, kutipan di atas menunjukkan aktivitas jasmani bidang makanan. Data berikut ini mnunjukkan aktivitas jasmani bidang pakaian.

Ia telah kenakan padaku kemeja-dada berenda, kaku, seperti terbuat dari selembar kalit penyu. Tak mungkin rasanya membongkok dengan kemeja dada ini. Gombaknya yang kaku seperti kulit sapi juga membikin leher segan untuk menengok. Memang maksudnya supaya badan tetap tegap, tidak sering menoleh, pandang lurus seperti gentlemen sejati (Bumi Manusia, 2019, hlm. I97).

Minke memakai pakaian rancangan Niccolo Morenoo yang dibuat khusus untuk Minke dan digunakan untuk acara pengangkatan bupati Ayah. Gaya pakaian yang digunakan Minke yaitu perpaduan Jawa Timur dan Madura. Desain yang dibuat sangat indah. Minke memakai pakaian tersebut menjadi terlihat lebih gagah. Keris bertahtakan permata yang dipasangkan di baju Minke menjadi sangat khas dengan budaya Jawa. Keris tersebut membuat tokoh lebih gagah dan menarik saat dilihat.

Berdasarkn hasil yang telah ditemukan, maka dapat disimpulkan bahwa dalam novel Bumi Manusia karya Pramoedya Ananta Toer terdapat beberapa kompleksitas aktivitas jasmani yang meliputi makan, minum, dan pakaian.

\section{Persantunan}

Penulis mengucapkan terima kasih kepada seluruh pihak yang telah berperan dalam membantu penelitian ini. Selanjutnya kepada tim editor Bahastra yang telah membantu publikasi artikel ilmiah ini.

\section{Simpulan}

Novel Bumi Manusia karya Pramoedya Ananta Toer yang menceritakan aktivitas kehidupan masyarakat Jawa. Aktivitas masyarakat Jawa terlihat dari pembahasan di atas yaitu, aktivitas kekerabatan ditunjukan dengan aktivitas tolong monolong, bertamu dan peduli satu dengan yang lain, aktivitas ekonomi ditunjukkan dengan aktivitas untuk melengkapi kebutuhan setiap orang, aktivitas pendidikan terdapat pada kegiatan formal yaitu Minke melakukan kegiatan di sekolah dan non formal yakni Minke belajar bahasa Inggris sebelum masuk sekolah.

Kemudian terdapat aktivitas keindahan dan rekreasi yang ditunjukkan dengan aktivitas seni gerak dan seni suara. Selanjutnya, aktivitas religi ditampilkan dengan aktivitas tokoh saat melangsungkan perkawinan dan saling menghargai saat tokoh akan makan makanan yang haram atau halal. Kemudian aktivitas politik yang terdapat dalam novel tersebut mengenai aktivitas dalam bidang pemerintahan dan organisasi.

Aktivitas kebutuhan jasmani ditunjukkan dengan aktivitas dalam bidang kebutuhan makanan, minuman, dan pakaian. Oleh karena itu, terdapat kompleksitas aktivitas masyarakat Jawa dalam novel Bumi Manusia karya Pramoedya Ananta Toer dengan kajian antropologi sastra.

\section{Daftar Pustaka}

Ashaley, K.M. (1990). Victor Turner and The Construction of Cultural Vritical (Between Literatureand Anthropology). Indian: University Press.

Bagea, I. (2016). Implementasi Nilai Budaya Sarapatanguna dalam Kepemimpinan Pemerintahan di Kota Baubau, Provinsi Sulawesi Tenggara. Jurnal Kandai, I2(2), 297-308.

Creswell, J.W. (2010). Research Design: Pendekatan Kualitatif, Kuantitatif, dan Mixed. Yogyakarta: Pustaka Pelajar.Djirong, S. (2014). Kajian antropologi sastra cerita rakyat Datumuseng dan Maipa Deapati. Jurnal Sawerigading, 20(2), 215-226.

Chrisman, N \& Maretzki, T. (1982). Clinically Applied Anthropology: Anthropologists in Health Science Settings. London: D. Reidel Publishing Company.

Haviland, W.A. (I995). Antropologi, Jakarta: Erlangga.

Ihromi. (2006). Pokok-pokok Antropologi Budaya. Jakarta: Yayasan Obor Indonesia.

Ihsan, B \& Zuliyanti, S. (2018). Kajian Antropologi Sastra dalam Novel Ranggalawe: Mendung di Langit Majapahit Karya Gesta Bayuadhy. Jurnal Pentas, 4(1), 33-40.

Juliastuty, D. (2013). Pemertahanan Budaya Tionghoa dalam Novel Kau, Aku dan Sepucuk Angpau Merah Karya Tere Liye. Jurnal Kandai, 9(2), 342-346.

Koentjaraningrat. (2015). Pengantar Ilmu Antropologi. Jakarta: Rineka Cipta.

Miles, M.B dan Huberman, A.M. (2012). Analisis Data Kualitatif. Jakarta: UI Press. 
Moleong, Lexy J. (2014). Metodologi Penelitian Kualitatif. Bandung: PT. Remaja Rosdakarya.

Rasyid, A.B.D. (2017). Lokalitas dalam cerita rakyat Datumuseng dan Maipa Deapati. Jurnal Sawerigading, 23(1), 25-37.

Ratna, N.K. (2012). Antropologi Sastra: Peranan Unsur-unsur Kebudayaan dalam Proses Kreatif. Yogyakarta: Pustaka Pelajar.

Perbawani A.A, Suwandi S, \& Subiyantor, S. (2019). The Cmplexity of Cultural Outcomes in Folklore the Legend of Payaman Cave (Anthropology Literature Study). American Journal of Humanities and Social Sciences Research, 3(8), 37-40.
Poyatos, F. (1988). Literary Anthropology. Amsterdam: John Benjamins Publishing Company.

Sahlan. (2012).Kearifan Lokal Pada Masyarakat Buton dan Relevansinya dengan Pendidikan Karakter. Jurnal El Harakah, 14(2), 312-325.

Siswantoro. (2005). Metode Analisis Sastra: Psikologi Sastra. Surakarta: Muhammadiyah University Press.

Toer, P.A. (2019). Bumi Manusia. Jakarta: Lentera Dipantara.

Waterston, A \& Vesperi M.D. (2011). Anthropology off the Shelf: Anthropologists on Writing. Singapore: Balckwell. 